\section{On the search for solutions}

\author{
Anthony Stone
}

Journal of Mathematical Chemistry. Editor Dennis H. Rouvray. Baltzer, Wettsteinplatz 10, CH-4058 Basel, Switzerland. $4 / y r$. SwFr 344.50, $\$ 222$ (institutional); SwFr 120, $\$ 77.50$ (personal).

MANY of the mathematical techniques of physics and chemistry can be applied to a wide variety of problems, and it sometimes happens that a development in one area turns out to have been anticipated somewhere else entirely. There is a case, therefore, for a journal in which such developments can be published. The Journal of Mathematical Physics has served such a purpose for many years, and it may be argued that because many basic techniques (such as group theory) are common to physics and chemistry, there is no need for a journal devoted specifically to the mathematical aspects of chemistry. But although the basic principles of group theory are common to high-energy physics and inorganic chemistry, the particular symmetry groups and applications are now so different that the fields have little in common. Moreover, modern chemistry depends more and more heavily on mathematics. In principle, then, the introduction of the Journal of Mathematical Chemistry is a sensible idea.

I was discouraged, though, to see that four of the eight papers in the first issue were on graph theory. This is a contentious subject, and here is not the place to discuss it, even if I were qualified to do so. However, three of the papers concerned deal with the graph-theory version of simple Hückel theory, which played an important part in its time but which has for years been recognized as a grossly inadequate model of electronic structure. I was surprised to see it suggested by one of the authors that Hückel himself derived his model from graph theory, which I believe to be quite untrue. In fact, graph theory has yet to contribute to the body of fundamental ideas that constitute the chemist's intuition.

In fairness it should be said that graph theory is not so prominent in the other three issues that I have in front of me. Some of the topics will be regarded as fairly esoteric by the average chemist knot theory of molecules and chirality polynomials, for instance - but there are also contributions concerned with statistical mechanics and thermodynamics, electronic structure, chemical equilibrium in multicomponent systems and the chemical kinetics of nerve synapses. The papers on knot theory and chirality polynomials are clear and well written, and are examples of the reviews which appear at the beginning of some issues. Such reviews serve a helpful function for chemists who are interested in finding out about mathematical developments that may be useful to them, and are a valuable feature of the journal. Nevertheless, I suspect that most chemistry library committees will decide that, at its not inconsiderable price, they can manage without it.

Anthony Stone is a Lecturer in Theoretical Chemistry, University Chemical Laboratory, University of Cambridge, Lensfield Road, Cambridge CB2 IEW, UK.

a high scientific standard both of these papers ( 43 of them) and of the 25 normally refereed papers published in the first year. The contributions have covered a wide range of topics in all areas of mass spectrometry, and the aim of rapid publication has been more than met; most papers are published within five weeks of receipt, compared with six to twelve months for the other main mass spectrometry journals (Organic Mass Spectrometry and The International Journal of Mass Spectrometry and Ion Physics). Each issue also contains a diary of meetings, while a new product section and book reviews are included from time to time.

This is a modestly priced, high-quality production which gives excellent value in terms of its scope and the quality of its contents. It is a 'must' on the reading list of all those involved in mass spectrometry and its applications.

Robin Thain Aplin is a Research Support Officer in the Dyson Perrins Laboratory, University of Oxford, South Parks Road, Oxford $O X 13 Q Y, U K$

\section{Going global}

\author{
Thomas J. Crowley
}

Climate Dynamics. Executive editors W.L. Gates and H. Oeschger. SpringerVerlag. 4/yr. DM282, $\$ 170$.

IN THE past ten years climate studies have evolved from being dominated by meteorologists into a discipline that incorporates physical oceanography, geochemistry, cryosphere-biosphere interactions and palaeoclimatology. Progress has been greatly stimulated by realization of the significance of anthropogenicinduced changes, especially the greenhouse effect. There have also been substantial theoretical advances which have stemmed in large part from the availability of supercomputers. As the field has branched out and matured, it has devel-

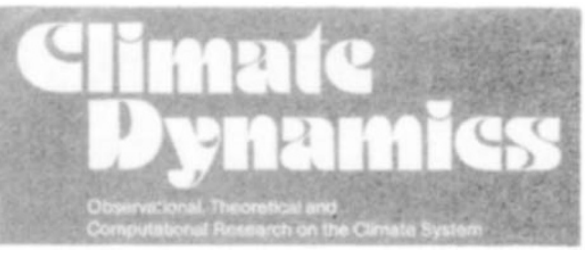

oped an identity different from traditional 'climatology'; thus the name 'climate dynamics'. It is now at the stage where it is one of the key building blocks of the emerging 'global change' programme.

To some extent, climate research has outgrown a number of the journals and organizations whence it evolved. Some articles are certainly still appropriate for the long-established journals, but others, especially those of an interdisciplinary nature, need a new forum. Climate Dynamics aims to meet that need, putting considerable emphasis on interdisciplinary work and on the importance of theoretical advances.

In the hope of giving the journal a strong start, the editors have assembled a distinguished group of scientists for their editorial board. With five issues now published, it is safe to say that in general their goals are being realized. Most of the articles are of good-to-high quality, and the topics wide-ranging, although studies of the greenhouse effect and of palaeoclimates have predominated. A sampling of article content gives evidence to the broad scope - coupled ocean-atmosphere models, an ocean-carbon cycle model, past deep-water circulation changes, instabilities in climate models, sea-ice parameterizations, transient effects of $\mathrm{CO}_{2}$ warming, ozone changes, analysis of historical data sets, and modelling of the African monsoon. To their credit, the editors have welcomed idealized mathematical models that often fall outside the limits of typical atmospheric science journals. Most of the 'sponsor referees', whose names appear after the title of the paper, has resulted in 